\title{
Turismo Infantil: uma proposta conceitual
}

\section{Tourism for children: a conceptual proposal}

\author{
Elizabete Sayuri Kushano (KUSHANO, E. S.) ${ }^{*}$
}

\begin{abstract}
RESUMO - O objetivo principal do presente trabalho foi o de propor um conceito de turismo infantil. Para tanto, se explanou sobre a infância como categoria social; se analisou a importância do turismo para a criança, bem como do público infantil para a atividade turística; $\mathrm{e}$, se apontou as principais atividades relacionadas ao turismo para crianças. Por meio de pesquisa bibliográfica e exploratória, foram destacados os benefícios socioculturais do turismo, entre os quais: que o contato direto com a natureza na infância tende a surtir efeitos positivos, que refletem as atitudes e o comportamento dos adultos que as crianças vão ser. Quanto à importância da criança para o turismo, destaca-se que as férias só para elas são um dos mercados emergentes no setor. Como atividades relacionadas ao turismo para crianças, caracterizou-se, por exemplo, o turismo pedagógico e os acampamentos de férias. Por fim, chegou-se a uma proposta conceitual de turismo infantil. Nessa forma de turismo, há necessidade de maior supervisão de profissionais, como também, adequação de produtos e serviços para atender as crianças com segurança e qualidade, proporcionando a elas percepção de novas paisagens, desenvolvimento pessoal, conforto, diversão e aprendizados culturais.
\end{abstract}

Palavras-chave: Criança; Infância; Turismo infantil; Proposta conceitual.

ABSTRACT - This study aims to introduce a conceptual proposal for tourism for children. In order to meet the goals for the study, the childhood was explained as a social category and the importance of tourism for children was analyzed. Through a bibliographical and exploratory research, the socio-cultural benefits of tourism were highlighted, such as: Traveling and the perception of landscape help children to develop their senses; the direct contact with nature in the childhood has a positive impact on children's behavior and attitudes: factor that can affect on what kind of adults children will be; the importance of tourism for children in the matter of self-esteem: children learn they are able to socialize, to meet new people and be well accepted; traveling with their parents, children have all the attention and feel more secure and attached to them. The importance of children for the tourism area was much discussed in this study: the tourism for children has been considered one of the most emerging market in the segment, specially the trips organized only for children, the pedagogical tourism and the summer camps. In the matter of this proposal, there is need for a greater supervision from professionals and an adjustment of products and services as well, in order to offer them security and quality, providing them perception of new landscapes, personal development, comfort, fun and cultural learning.

Key words: Child; Childhood; Tourism for children; Conceptual proposal.

\footnotetext{
* Graduação em Turismo (Bacharelado) pela Universidade Federal do Paraná (UFPR). Especialização em Turismo e Meio Ambiente pela Faculdade Estadual de Ciências e Letras de Campo Mourão (FECILCAM). Mestrado em Cultura e Turismo pela Universidade Estadual de Santa Cruz (UESC). Doutoranda em Geografia pela UFPR. Professora da UFPR Setor Litoral. Endereço para correspondência: Rua Jaguariaíva, 512, Bairro: Caiobá. CEP: 83260-000 - Matinhos - áraná (Brasil). E-mail: sayuritur@gmail.com
} 


\section{INTRODUÇÃO}

A Organização Mundial do Turismo (OMT) ${ }^{1}$, anunciou no primeiro semestre de 2012 que este seria o ano que o número de turistas ao redor do mundo ultrapassaria um bilhão (OMT, 2012).

O discurso quantitativo do turismo empolga a economia global, porém, há que se pensar, também, na questão qualitativa em consonância com uma atividade e um fenômeno social mais justo, equânime e para todos; enfatizando, conforme Bahl (2012), os benefícios advindos do turismo.

$\mathrm{Na}$ perspectiva dos estudos de humanização das atividades turísticas que preconiza o turismo para todos, Wainberg $(2002$, p. 1) discorre que:

\footnotetext{
Turismo é um fenômeno complexo, com facetas social, econômica e psicológica [...]. É um setor que impacta um largo número de indivíduos. Não só o governo ou negociantes são os atores decisivos do fenômeno, mas gente; gente de carne e osso.
}

A expressão "gente de carne e osso" suscita à função e responsabilidade social de empresas e organizações, ao envolvimento da comunidade, como também, ao turismo para todas as pessoas. Conforme Aguirre et al. (2003), o "para todos" não se refere somente a pessoas com deficiências permanentes, mas a pessoas com limitações e necessidades temporárias, como idosos e crianças.

Como fenômeno social e aliado ao forte apelo econômico e mercadológico, o fato é que o turismo tem se profissionalizado, melhorando a qualidade de seus produtos e serviços. Observa-se um setor com mais gestores dispostos a descobrir e satisfazer os desejos e as necessidades do cliente turista, o que o conduz a estar atento às tendências do mercado.

Uma das tendências do mercado é a segmentação, estratégia que permite a identificação e a análise dos consumidores reais e potenciais. Dentre as características de segmentação, está o aspecto demográfico, sendo a faixa etária de um grupo homogêneo de indivíduos um de seus principais focos. Deste modo, tem-se o turismo de

\footnotetext{
${ }^{1}$ Em inglês: UNWTO - World Tourism Organization.
} 
juventude, o turismo de terceira idade, assim como o turismo infantil, foco desse trabalho.

Partindo da premissa de que as crianças participam de atividades turísticas e por isso são consumidoras de produtos e serviços turísticos - sejam eles exclusivamente direcionados ou adequados para elas, seja viajando em família ou por meio do turismo pedagógico (junto com professores e colegas), e também em grupos de mesma idade, como nos acampamentos e colônias de férias - percebe-se que também exercem um papel social: o de turista.

Em paralelo, torna-se importante mencionar que no Brasil existem agências especializadas em pacotes turísticos para a terceira idade. Também, nota-se que alguns meios de hospedagem oferecem estrutura, alimentação e programação direcionada para tal faixa etária (FROMER; VIEIRA, 2003). Observa-se, desse modo, que os agentes do mercado turístico têm demonstrado preocupação em atender a terceira idade, ofertando produtos e serviços conforme as necessidades, os desejos e as ansiedades de tal público; nota-se nos praticantes dessa forma de turismo, um aumento na autoestima, na qualidade e motivação para a vida (SILVA, 2002).

Portanto, cabe direcionar o olhar, também, para o turismo da criança ou o turismo infantil, surgindo as seguintes indagações: Como a atividade turística tem se adequado para atender a criança enquanto turista? Qual a contribuição do turismo para a sociabilidade da criança? Quais as atividades comumente relacionadas ao turismo para as crianças? O que vem a ser o turismo infantil?

Os conceitos encontrados para turismo infantil se limitam a situá-lo como o turismo praticado por crianças, delimitando a idade, como em Vaz (1999), que aponta para a faixa etária dos sete a treze anos. Diante de tal realidade, se justifica a importância de um conceito mais atento ao sujeito criança, especialmente por se tratar de um ser em formação.

O objetivo do presente trabalho é propor um conceito para turismo infantil. Para tanto se faz uma revisão bibliográfica sobre os temas infância e criança, abarcando-os como categoria social. A seguir, se analisa a importância do turismo para a criança, bem como a importância das crianças para a atividade turística. Posteriormente, se elenca as principais atividades relacionadas ao turismo para crianças. Por fim, chega-se a uma proposta conceitual para turismo infantil. 


\section{CRIANÇAS E SUAS INFÂNCIAS}

A história social das crianças indica a construção do termo "criança", de acordo com o limiar do tempo e suas transformações na sociedade (ARIÈS, 1981; SARMENTO e PINTO, 1997). De forma geral, esses estudos esclarecem que o sentimento de infância, de preocupação e investimento da sociedade e dos adultos sobre as crianças, de criar direitos, deveres e, principalmente, o papel social da infância e da família são ideias que surgem com a modernidade. Neste sentido, a infância como categoria social é uma ideia moderna (SARMENTO, 2004; 2003).

O historiador francês Ariès (1981) constata a ausência do sentido de "infância", tal como um estágio específico do desenvolvimento do ser humano, até o fim da Idade Média, onde a criança era considerada um adulto em miniatura. Comenta que a perda de uma criança causava tristeza, mas era encarada como algo substituível. Naquela época, o índice de mortalidade infantil era grande e se acreditava que o nascimento de outra criança substituiria a que tinha partido (ARIÈS, 1981).

A construção do conceito de infância, como é conhecido na atualidade, transita nos séculos XVII e XVIII, quando ela passa a ser definida como um período ingênuo e frágil do ser humano, que deve receber todos os incentivos possíveis para ser feliz. (ARIÈS, 1981). Além disso, o autor discorre que a morte de uma criança também passa a ser recebida com muito pesar, dor e sofrimento.

Uma característica marcante da história da infância no Brasil diz respeito ao tratamento dispensado às crianças. Há relatos de sofrimento e violência, porém, destacam-se as passagens que retratam as dolorosas separações entre pais e filhos. "Os viajantes estrangeiros não cessaram de descrever o demasiado zelo com que, numa sociedade pobre e escravista, os adultos tratavam as crianças", comenta Del Priore (2000, p. 11).

"Criança" e "infância" continuam sendo palavras complexas na sociedade atual. Uma sociedade dita pós-moderna, consumidora, capitalista e com pensamento em rede. Assim sendo, Kuhlmann Jr. e Fernandes (2004) apontam que a palavra “infância” evoca um período da vida humana no limite da significação, o período de construção/apropriação de um sistema pessoal de comunicação, de signos e de sinais destinados a fazer-se ouvir. Para os autores, o vocábulo "criança" indica uma realidade 
psicobiológica referenciada ao indivíduo. Steinberg e Kincheloe (2001, p. 11), sintetizam, dizendo que o universo da infância é "um artefato social e histórico e não uma simples entidade biológica".

Em muitos países, costuma-se distinguir o indivíduo criança do indivíduo adolescente e do adulto, de acordo com a faixa etária. No Brasil, segundo o Estatuto da Criança e do Adolescente (BRASIL, 1990) considera-se criança o indivíduo entre zero a doze anos de idade incompletos.

Para Prout (2005, p. 144), a infância tem múltiplos significados que, em uníssono, a caracterizam em um amplo, porém, denso sentido:

[...] Childhood should be seen as neither 'natural' nor 'cultural' but a multiplicity of 'nature-cultures', that is a variety of complex hybrids constituted from heterogeneous materials and emergent through time. It is cultural, biological, social, individual, historical, technological, spatial, material, discursive [...]. Childhood is not to see as a unitary phenomenon but a multiple set of constructions emergent from the connection and disconnection, fusion and separation of these heterogeneous materials ${ }^{2}[\ldots]$.

Ao pensamento de Prout que trata das muitas infâncias existentes, acrescenta-se a reflexão sobre o ser criança e estar criança, além do que é ter infância e para quais indivíduos é permitido tal "privilégio". Nesse sentido, Pereira e Souza (2005, p. 37) exprimem a angústia da maioria das crianças contemporâneas, principalmente as de classe média a alta:

Criança pequena com agenda lotada. A televisão que se transforma em babá. Os pais ausentes. Carinho transformado em objeto [...] a afetividade objetificada. Erotização da infância. Sexualidade. Publicidade. Cultura do consumo [...]. Individualismo desencadeado pela ausência do outro. Apagamento da relação de alteridade. Criança sozinha. Criança que manda nos pais.

As crianças com agenda lotada parece algo tão evidente que muitas pessoas conscientes de tal prática, vêm desmotivando os pais ou responsáveis a tal comportamento, para que promovam para seus filhos uma infância com equilíbrio entre

\footnotetext{
${ }^{2}$ A infância não deve ser vista nem como 'natural', nem como 'cultural', mas como uma multiplicidade de 'natureza-culturas', que é uma variedade de híbridos complexos constituídos a partir de materiais heterogêneos e emergentes ao longo do tempo. A infância é cultural, biológica, social, individual, histórica, tecnológica, espacial, material, discursiva [...]. A infância não é para ser vista como um fenômeno unitário, mas como um conjunto múltiplo de construções emergentes de conexão e desconexão, de fusão e separação destes materiais heterogêneos (tradução nossa).
} 
o dever e o lazer. Tanto que, no Dicionário do Futuro, Popcorn e Hanft (2002) fazem menção às "crianças de vida livre", ou seja, a necessidade de uma nova geração de crianças criadas sem excesso de programação.

Pelo exposto, observa-se que a criança é concebida na sua condição de sujeito histórico, que verte e subverte a vida e a ordem social (KRAMER, 1996). Nesse sentido, o presente trabalho irá tratar, a seguir, das crianças exercendo o papel social de turista, analisando a importância do turismo para as crianças, bem como do público infantil para a atividade turística.

\section{A IMPORTÂNCIA DO TURISMO PARA AS CRIANÇAS}

No artigo 71 do Estatuto da Criança e do Adolescente (BRASIL, 1990) consta que "a criança e o adolescente têm direito a informação, cultura, lazer, esportes, diversões, espetáculos e produtos e serviços que respeitem sua condição peculiar de pessoa em desenvolvimento". Nesse sentido, a prática do turismo insere-se como uma atividade capaz de proporcionar informação, cultura, lazer e diversão para as crianças, além de uma proposta de aprendizado cultural por meio da educação nos níveis formal e não formal.

Comumente, tem-se abstraído o brincar, a produção cultural das crianças, substituída pela produção cultural para as crianças. O estresse infantil, distúrbios de aprendizagem, entre outros, podem ser sintomas de que algo não vai bem, em se tratando do lazer das crianças. Marcellino (2006) observa que é fundamental que se assegure às crianças o tempo e o espaço para que o caráter lúdico do lazer seja vivenciado com intensidade capaz de formar a base sólida para a criatividade e a participação cultural e, sobretudo, para o exercício do prazer de viver.

O viajar e a percepção da paisagem fazem parte do próprio desenvolvimento ${ }^{3}$ dos sentidos na infância. Deste modo, Tuan (1980) reflete sobre a diferente visão de mundo, da evolução do sistema perceptivo que as crianças apresentam ao longo dos

\footnotetext{
${ }^{3} \mathrm{O}$ conceito de desenvolvimento, comumente empregado ao se tratar da infância, é compreendido aqui, conforme a perspectiva de Vigotsky (1991), como um processo social que prossegue por toda a vida, com ou sem escolarização, e que se dá por meio da mediação e da interação com o outro. Nesse sentido, indo ao encontro da visão social e histórica da infância, já anteriormente expostas.
} 
anos. A percepção da paisagem requer, antes de tudo, as habilidades de fazer distinção nítida entre o eu e os outros e de avaliá-la esteticamente; habilidades essas ainda pouco desenvolvidas nas crianças menores de seis anos de idade. Apesar de a paisagem escapar dos seus vários componentes: um toco de árvore, água borbulhando num trecho de córrego, dentre outros. Já uma criança acima de sete ou oito anos é capaz de conceituar o espaço em suas diferentes dimensões, gosta das sutilezas nas cores e reconhece as harmonias na linha e no volume. (TUAN, 1980). Ainda, conforme o mesmo autor, nessa fase, as crianças estão, vibrantemente, abertas para o mundo. Assim, a percepção diferenciada das crianças sugere que elas, como turistas, mereçam atenção também diferenciada. Conhecer o universo particular das crianças é uma maneira de respeitá-las e conquistá-las (KUSHANO, 2008).

Referente aos estudos da percepção da criança, as pesquisadoras Wells e Kristis (2006) analisam as dimensões da influência da natureza sobre crianças. Segundo elas, o contato direto com a natureza na infância tende a surtir efeitos positivos, que refletem as atitudes e o comportamento dos adultos que as crianças vão ser. Por meio de entrevistas com duas mil pessoas, com idades variando dos 18 aos 90 anos, as pesquisadoras testaram a possível relação entre o grau de envolvimento infantil com a natureza e as atitudes e os comportamentos em questões ambientais na idade adulta. A pesquisa demonstrou que acampamentos, brincadeiras no mato, caça e pesca, figuram entre as principais atividades a fundar os alicerces de um futuro ambientalista. Mas, também serve colher flores, plantar árvores ou sementes e cuidar de plantas em casa, ou seja, manter contato com a "natureza domesticada".

Crianças residentes em grandes centros urbanos costumam ter pouco contato com a natureza. Dessa forma, os passeios e as viagens em que o contato com a natureza esteja na programação serão aprazíveis e importantes para a consciência ambiental e o desenvolvimento cultural dessas crianças.

Educação ambiental e interação com a natureza junto às crianças têm sido oferecidas em agências especializadas, especialmente as de ecoturismo e as de aventura. Nesse sentido, é importante observar as estratégias mercadológicas de algumas agências de turismo de aventura. Um exemplo é a Alaya, localizada na cidade paulista de Brotas. A agência convida os pais com filhos pequenos a conhecerem Brotas para praticarem esportes da natureza e indica que as crianças podem experimentar o mini-arvorismo 
com equipamentos e monitoria adequados aos mini-aventureiros, bem como respeitando as normas de segurança vigentes. (ALAYA, 2012).

Em se tratando do desenvolvimento cultural, observa-se que a Educação Patrimonial busca levar as crianças a um processo ativo de conhecimento, apropriação e valorização de sua herança cultural, capacitando-as para um melhor usufruto desses bens e propiciando a geração e a produção de novos conhecimentos, num processo contínuo de criação cultural (HORTA et al., 1999).

A Educação Patrimonial é um instrumento de "alfabetização cultural", que possibilita ao indivíduo fazer a leitura do mundo que o rodeia, levando-o à compreensão do universo sociocultural e da trajetória histórico-temporal em que está inserido. (HORTA et al., 1999). Esse processo leva ao reforço da autoestima dos indivíduos e comunidades e à valorização da cultura brasileira, compreendida como múltipla e plural.

Stoppa (1999) avalia que as programações de lazer e viagens para crianças devem, sempre que possível, conter aprendizados culturais e práticas pedagógicas. Especialmente em acantonamentos ${ }^{4}$ e demais programas direcionados exclusivamente para as crianças, o momento é propício para se aprender com diversão. Já Flores (2002) acrescenta que o distanciamento da família, por um tempo, é muito saudável e se constitui numa vivência de formação e informação, que fará muito bem para o amadurecimento social da criança. Tem-se, por exemplo, o aumento da autoestima, visto que a criança se descobre e se percebe capaz de realizar tarefas, de conviver com pessoas diferentes e de ser benquista.

Ademais, "a programação para o público infantil deve proporcionar vivências múltiplas e ser adaptadas conforme a faixa etária" destacam Negrine, Bradacz e Carvalho (2001, p. 67). Atividades na piscina (caça-trecos, natação, polo aquático), atividades de artes (pintura, sucata, reciclagem, dobraduras), gincanas, piqueniques, bingo infantil, teatrinho, leituras de contos, brincadeiras de disfarces, jogos esportivos, videokê, mímica, jogos de caça ao tesouro, almoços e jantares infantis (dando descanso para os pais na hora da alimentação), são consideradas de interesse para as várias fases da infância.

\footnotetext{
${ }^{4}$ Conforme Pimentel (2003), acantonamento consiste na ida a um local com acomodações prontas, mesmo que rústicas. Já o acampamento é realizado com barracas.
} 
Nota-se que muitos pais incentivam seus filhos a participarem de colônias de férias ou acantonamentos, com o intuito de ajudá-los a vencer a timidez ou outros traços de personalidade (FLORES, 2002). Porém, algumas vezes, o efeito contrário é observado. "A experiência pode ser dolorosa, irreversível e traumatizante", salienta Flores (2002, p. 105). As crianças tímidas podem "se fechar" ainda mais, rejeitando participar das atividades propostas, sentindo-se isoladas ou com medo e vergonha de conviver com pessoas diferentes. Desse modo, a responsabilidade e o tato dos profissionais em saber lidar com situações assim, como também conscientizar os pais sobre a ajuda continuada de outros profissionais, tais como psicoterapeutas e pedagogos, podem se fazer necessários para que as crianças tenham mais autoestima e vençam a timidez.

Em suma, a prática do turismo, pode propiciar independência às crianças turistas, como também momentos de cumplicidade e descontração com seus pais. Quando planejada de modo adequado e executada por profissionais qualificados, permitirá o desenvolvimento pessoal, a percepção de novas paisagens e aprendizados ao público infantil.

\section{A IMPORTÂNCIA DAS CRIANÇAS PARA O TURISMO}

Os agentes do setor de turismo começam a demonstrar maior atenção aos consumidores mirins. Exemplo disso é a afirmativa, conforme Swarbrooke (2002) de que as férias só para crianças são consideradas um dos mercados emergentes em turismo, assim como o fenômeno das reservas diretas, as férias com serviços all inclusive, o mercado de casamentos internacionais, o ecoturismo e os cruzeiros econômicos. Além de influenciar na escolha dos destinos das férias da família, a atividade turística proporciona férias infantis exclusivamente para crianças desacompanhadas dos pais.

No Brasil, o Guia Quatro Rodas (2008) apontou 2007 como um marco, em que os hotéis, os resorts e as pousadas, criaram novos espaços para o lazer infantil, aumentaram o treinamento e a especialização de equipes de lazer e apuraram os cardápios mirins. $\mathrm{O}$ Guia destacou algumas categorias de determinados 
empreendimentos hoteleiros, tais como: o quarto temático todo cor-de-rosa e conjugado ao quarto dos pais; o chá da tarde que a hóspede pode oferecer, em sua suíte, para as amiguinhas do resort; restaurante infantil e/ou cardápio infantil.

As crianças contribuem para o aumento das atividades de lazer e recreação, especialmente em hotéis de lazer e resorts, consequentemente, criando a necessidade de ampliar o rol de funcionários capacitados para planejar e executar atividades para esse público; ou mesmo, terceirizando tais serviços. Ter atividades de lazer, além de contribuírem com o bem-estar e a atitude lúdica inerente às crianças, aconchegam os pais, que se permitem dispor de horas de despreocupação sem os filhos.

Referente às famílias, faz-se importante notar que tal conceito costuma variar de acordo com a cultura de vários países ou continentes. Em muitas partes do mundo, a família típica é constituída com os dois pais e de um a três filhos (núcleo familiar). (SWARBROOKE, 2002). Ademais, observa-se o aumento de pais ou mães solteiros e com um único filho (GIDDENS, 2003).

De acordo com este último autor, a família é uma instituição incrustada, posto que permanece com o mesmo nome, mas a sua estrutura e funções se modificaram. Incutir e transmitir valores, colaborar na construção de uma vida com qualidade e proporcionar segurança são algumas das funções da família.

Muitas famílias escolhem férias que satisfaçam às necessidades dos filhos, necessidades essas que variam conforme a idade. Por exemplo, a tendência dos pais com bebês é a de escolherem hotéis e companhias aéreas que ofereçam serviços especiais, tais como comida para bebês (SWARBROOKE, 2002). Complementando tal raciocínio, Cobra (2005) aborda que, em se tratando de viagens a turismo, uma família com filhos pequenos, que não vão à escola, compra diferentemente de uma família com filhos em idade escolar, visto que a época de férias costuma interferir. Cooper et al. (2001), acrescentam que na infância outras pessoas tomam as decisões pelas crianças. Porém, muitas delas têm forte influência sobre os pais.

Esses apontamentos indicam que os agentes do mercado turístico devem estar atentos ao nicho de mercado das famílias, em especial, as com filhos pequenos, pois além de eles influenciarem na decisão da compra, são decisivos para os pais, em termos de escolhas de produtos e serviços turísticos que tenham adequações para eles. Nesse sentido, explica-se a preferência de muitas famílias por férias self-catering 
(autoabastecimento), em parte, pelo desejo de minimizar os custos das férias, mas também resulta do desejo que algumas famílias têm de fugir às regras de etiqueta e às formalidades próprias à hospedagem em hotéis e à necessidade de fazer refeições em horários rígidos, visto que "as crianças costumam ter dificuldades de se adaptar a regimes tão rigorosos" (SWARBROOKE, 2002, p. 197).

Ainda segundo o mesmo autor, os agentes do mercado turístico também necessitam levar em conta as viagens exclusivas de crianças. Sendo o aumento das crianças que viajarão em grupos de pessoas pertencentes à mesma faixa etária, uma tendência.

O exposto acima indica a necessidade em adequações físicas e humanas, ou seja, produtos e serviços exclusivos e direcionados para o público infantil, como também, profissionais capacitados para atendê-las (KUSHANO, 2008). As singularidades existentes no universo infantil sugerem que produtos e serviços necessitam ser especialmente planejados e adequados aos pequenos consumidores, para que lhes sejam atrativos, seguros e úteis (KUSHANO, 2007).

No tópico seguinte serão destacados os tipos de atividades comumente relacionadas ao turismo infantil com o intuito de buscar caracterizá-las.

\section{TIPOS DE ATIVIDADES RELACIONADAS AO TURISMO INFANTIL}

Dentre as principais atividades relacionadas ao turismo infantil, destacam-se os acampamentos de férias, os acantonamentos, a hospedagem em hotéis de lazer e resorts, a diversão nos parques temáticos e o turismo pedagógico.

Para Peñalba (1999), acampamento de férias é uma atividade ou evento recreativo de caráter intensivo e temporalidade limitada a um curto período, planejada e organizada por uma equipe de animadores e dirigida a crianças ou jovens dispostos a viver juntos em um lugar diferente, preferivelmente em meio à natureza. Geralmente, não dispõe de infraestrutura similar às urbanas, utilizando-se barracas para dormir.

Civatate (2000, p. 9) assim conceitua o acampamento organizado:

É um método educativo de singular eficácia para todas as faixas etárias, em especial para menores e jovens. Uma temporada de acampamento constitui uma microexperiência comunitária que cria a consciência dos direitos e deveres do cidadão dentro da macrocomunidade em que vive. 
Ainda, de acordo com Civatate (2000) os objetivos dos acampamentos são: promover a higiene mental, a saúde, a socialização, o desenvolvimento do caráter pessoal, a aprendizagem, os valores ecológicos e os valores democráticos.

O termo "acantonamento", muitas vezes confundido com acampamento ou colônia de férias, refere-se a locais que possuem uma infraestrutura básica (cozinha, banheiro, luz, água corrente, quartos, dentre outras), geralmente feita para esse tipo de atividade (ÁVILA, 2006). Nos acantonamentos é comum as crianças não prepararem suas refeições, mas possuírem tarefas organizacionais que fazem parte do planejamento educativo, como por exemplo: arrumar quarto e manter o ambiente limpo. Ainda que os acantonamentos apresentem infraestrutura e facilidades típicas da vida urbana, deve-se tentar possibilitar que os participantes mantenham um amplo contato com a natureza. Por apresentar infraestrutura básica, são indicados para crianças a partir de sete anos. (ÁVILA, 2006).

Pimentel (2003, p. 57) sintetiza discorrendo que "acampamento é realizado com barracas enquanto acantonamento consiste na ida a um local com acomodações prontas, mesmo que rústicas". O referido autor (2003, p. 58) conceitua colônia de férias como uma "programação, em tempo integral ou parcial, realizada entre 5 a 30 dias, na qual as pessoas desenvolvem interesses recreativos, artísticos e esportivos de cunho coeducativo". As colônias de férias podem ocorrer em fazendas, escolas, hotéis, quartéis, acampamentos, estâncias balneárias, escolas, dentre outros lugares.

Uma organização que realiza acampamentos e acantonamentos educativos é a União dos Escoteiros do Brasil. Como um movimento de proposta educacional alternativa, os escoteiros entram em contato com a natureza, organizam atividades fora de suas sedes, promovem reuniões nacionais e internacionais, movimentando milhares de jovens (UNIÃO DOS ESCOTEIROS DO BRASIL, 2012).

Outros tipos de meios de hospedagem em que os seus gestores têm demonstrado atenção às crianças são os resorts e os hotéis de lazer. Comumente não são exclusivos para as crianças, porém oferecem adequações para elas, a fim de conquistar o público das famílias com filhos pequenos, o que proporciona comodidade para os pais e diversão para as crianças.

Os serviços de alimentação oferecidos no setor hoteleiro também estão sendo adequados ao público infantil. Castelli (2000) avalia que em um serviço de bufê é mais 
prático compor uma alimentação que agrade às crianças. Porém, o mesmo não acontece em um restaurante com o serviço à la carte. Nesse caso, aconselha-se confeccionar um cardápio infantil que deve obedecer a alguns princípios: a carta deve possuir um visual atraente para as crianças, podendo ser, inclusive, levada para casa, se for do desejo delas (CASTELLI, 2000). Prossegue afirmando que os termos nelas utilizados devem ser simples e de fácil compreensão, as porções devem ser adequadas às crianças e o preço ajustado a tais porções, a oferta de pratos deve ser limitada (três a seis pratos), para evitar confusões.

Outro serviço que tem sido visto com maior frequência é o de baby sitter. Geralmente ele faz parte do planejamento do setor de lazer dos hotéis e é mister que seja divulgado, para que os casais que tenham filhos pequenos possam utilizá-los, se assim o desejarem. Ademais, o serviço de baby sitter deve ser supervisionado pela coordenação do setor de lazer ou por alguém que a direção do hotel determinar, haja vista que é muito grande a responsabilidade de atender crianças na faixa etária de zero a quatro anos de idade (NEGRINE; BRADACZ; CARVALHO 2001).

Com relação aos parques temáticos, Alcobia (2004) descreve parque temático como a visitação e vivência junto à variada gama de entretenimento, diversão, hospitalidade e os demais serviços que esse oferece. $\mathrm{O}$ mesmo autor aponta alguns parques no Brasil, por exemplo: o Parque da Mônica, localizado em São Paulo (SP) e criado por Maurício de Sousa, que imaginou o parque seguindo o modelo Disney, para ser lar dos seus personagens (Mônica e sua turma); o Beto Carrero World, localizado no município de Penha, em Santa Catarina (SC), que tinha a presença de um personagem vivo de forte presença na mídia, o caubói brasileiro Beto Carrero; e o Hopi Hari, localizado em Vinhedo (SP), que apresenta a caracterização de países com particularidades próprias, como hinos, bandeiras e idiomas. Muitos desses parques temáticos têm alas radicais, planejadas para atrair o público jovem e adulto, porém eles conservam áreas propícias às crianças, com brinquedos e diversões adequados a elas (ALCOBIA, 2004).

Em se tratando do turismo pedagógico, relata-se que é uma prática relativamente nova no Brasil. Nos anos 80, cresceu o número de agências especializadas no trabalho junto às escolas, culminando nos anos 90, com a conscientização de dirigentes de várias escolas quanto à importância da viagem para o aprendizado dos alunos (ANDRIOLO; 
FAUSTINO, 1999). Ademais, os professores das próprias escolas têm se organizado para realizar viagens pedagógicas. Sobre esse assunto, Pelizzer (2004, p. 54) comenta: “embora muitas agências estejam operando esses produtos, podemos observar um crescente desvio da atividade. Ela é gerenciada diretamente pelas escolas, que atuam como agências de turismo, sem a necessária competência e o devido credenciamento".

O fim maior do turismo pedagógico não é a utilização dos equipamentos e serviços turísticos e sim, o processo educativo, sendo a experiência turística um meio de melhorar o nível de aprendizagem dos alunos. Portanto, diz-se que tal tipo de turismo serve às escolas em suas atividades pedagógicas. (ANDRIOLO; FAUSTINO, 1999). Ele acontece no período letivo e tem o status de "aula com animação" (SPÍNOLA DA HORA; CAVALCANTI, 2003). Porém, nota-se que o turismo pedagógico extrapola a esfera escolar, sendo praticado também em associações, clubes, escolas de idiomas, entre outros locais.

O termo "turismo pedagógico" também é chamado de "turismo educacional". Segundo contido em OMT (2003), embora todo turismo possa ser considerado educativo, no sentido de que o visitante aprende sobre a cultura, a sociedade e outros aspectos do destino, o termo referido geralmente diz respeito a viagens nas quais a aprendizagem acontece de forma programada e estruturada. Essa organização acrescenta ainda que:

Certos roteiros podem ser considerados como turismo educacional, pois são voltados para locais históricos, culturais ou científicos importantes, e muitas vezes são coordenados por um professor especializado. Ao contrário da simples visita a locais turísticos, os roteiros educacionais podem incluir livros, palestras e outros materiais complementares para criar uma experiência de aprendizagem mais formal (OMT, 2003, p. 91).

No entanto, para Pelizzer (2004, p. 54) "a tendência do turismo pedagógico enquadra-se na percepção da potencialidade do turismo como processo informal de educação" e acrescenta que o turismo é uma das alternativas do processo não formal de ensino e aprendizagem, quando planejado, organizado, administrado e aplicado com profissionalismo. Ademais, também comenta que "o turismo responde a uma necessidade de as escolas mudarem seu posicionamento, sendo um eficiente canal para a educação informal ou não formal". 
O Sítio do Carroção (2012) é um exemplo de meio de hospedagem com características pedagógicas. Ele é exclusivo para crianças e jovens de 5 a 16 anos e está localizado em Tatuí, (SP). Foi inaugurado em 1974 e tem atrações como o sítio arqueológico, com fóssil do Tiranossauro rex, além da caverna artificial, do minizoológico e do aquário de peixes brasileiros e jacarés.

Outra atividade em expansão destinada ao público infantil é a visitação a museus. Nesse sentido, alguns museus têm-se adequado para atender a grupos de crianças.

Sobre a gestão dos museus, Pires (2002, p. 37) avalia que:

\begin{abstract}
Os museus modificaram-se bastante, agregando atividades antes sequer imaginadas. Posturas novas foram implantadas com o objetivo de integrar a comunidade ao museu, mediante visitas guiadas levando-se em conta o interesse dos visitantes, com aulas de pintura, decoração, teatro, exposições de obras de autores da própria localidade e muito mais. Uma nova concepção o transformou em um espaço de educação extraclasse, contribuindo, desta forma, para o cumprimento de uma das suas grandes metas: a pedagógica.
\end{abstract}

Desse modo, a concepção de museu como um lugar atraente para visitação turística é um dos objetivos e desafios da gestão criativa dos museus. Torná-los atrativos às crianças, assim como para os demais públicos-alvo, requer adequações, tais como funcionários capacitados, atividades e folhetaria direcionada, dentre outros aspectos.

Finalizando os tipos de atividades relacionadas ao turismo infantil, destaca-se que a preocupação com a segurança das crianças ao praticarem atividades turísticas deve ser uma característica constante nessa forma de turismo. A organização não governamental Férias Vivas alerta para a necessidade de segurança e aos cuidados redobrados com as crianças em férias, incentivando a presença de monitoramento nas atividades infantis (FÉRIAS VIVAS, 2012).

\title{
6 TURISMO INFANTIL - UMA PROPOSTA CONCEITUAL
}

No presente trabalho, com aportes na Sociologia e na História da Infância, o termo "Infância" foi exposto com múltiplos sentidos, sendo mais apropriado (embora 
ainda mais complexo) falar em "infâncias", visto que há uma variedade de híbridos complexos construídos a partir de materiais heterogêneos e através do tempo (ARIÈS, 1981). A infância é dita como cultural, biológica, social, individual, tecnológica (PROUT, 2005), enquanto o termo “criança" remete à condição psicobiológica do sujeito (STEINBERG, S. R.; KINCHELOE, 2001).

Posto isto, a proposta conceitual apoia-se nos resultados outrora apresentados referentes à importância do turismo para a infância, bem como a importância da infância para o turismo. A essa relação dialógica, acrescenta-se o elenco das características dos tipos de atividades comumente ligadas ao turismo infantil.

Em que pese a importância do caráter inédito por se tratar de uma proposição, em complemento, foi realizada uma busca pela Internet, no que se refere aos sítios eletrônicos de livros especializados em turismo, como é o caso do: "Livros de Turismo" (2012). Nessa ferramenta, nenhuma ocorrência foi encontrada em se tratando dos termos 'turismo infantil', 'turismo para crianças' e 'criança turista'; indicando uma incipiência na produção bibliográfica sobre o tema.

No sítio eletrônico "Publicações de Turismo" (2012), ao se digitar a palavrachave "turismo infantil" foram encontrados dois artigos em periódicos. Um deles é "Segmentação de mercado: uma abordagem sobre o turismo em diferentes faixas etárias" (SILVA; KUSHANO; ÁVILA, 2007), no qual os autores (dentre eles a autora deste artigo) abordam o turismo infantil, porém não chegam a propor um conceito. No outro: 'Uso da cartilha 'Aventura da vida nas cavernas' como ferramenta de educação nas atividades de turismo em paisagens cársticas" (FERREIRA et al., 2008) os autores fazem menção à cartilha como propícia para o público infantil, contudo também não tecem uma conceituação de turismo infantil.

Como constatado, raros são os trabalhos em que se conceitua o turismo infantil e quando o fazem se limitam a situá-lo como o turismo praticado por crianças, ou seja, delimitam apenas a faixa etária do grupo, geralmente de sete a treze anos (VAZ, 1999); sem considerar, por exemplo, a importância de produtos e serviços adequados para o público infantil, além da questão da segurança, do desenvolvimento pessoal, entre outros. Talvez, a incipiência nos estudos e pesquisas referentes ao turismo infantil reflita sobre a própria realidade do mercado, sendo recente a atenção às adequações necessárias para as crianças. 
O Estatuto da Criança e do Adolescente menciona que "criança" é o indivíduo entre zero a doze anos de idade incompletos. Em Kushano (2008) foi verificado que o mercado tem adotado o critério da faixa etária quando se refere às crianças, especialmente em se tratando de promoções e descontos para o público infantil em meios de hospedagem; tendendo a diminuir o limite de idade para tais descontos a no máximo sete anos.

Urge considerar a criança como consumidora e cidadã (CANCLINI, 1999), elevando a atividade turística como importante para o aprendizado cultural e o lazer infantil. Nesse sentido, alarga-se a proposta conceitual de turismo infantil, que deve atentar para um tipo de turismo praticado por crianças e para as crianças.

Baseado no exposto apresenta-se uma proposta conceitual para turismo infantil, que consiste em considerar que é o turismo praticado por crianças e planejado para as crianças; estejam elas em grupos de sua própria idade ou acompanhadas de pais e/ou responsáveis; sendo os acampamentos de férias, os acantonamentos, a hospedagem em hotéis de lazer e resorts, a diversão nos parques temáticos e a prática do turismo pedagógico as principais atividades relacionadas ao mesmo. Nessa forma de turismo, há necessidade de maior supervisão de profissionais, como também, adequação de produtos e serviços para atender as crianças com segurança e qualidade, proporcionando a elas percepção de novas paisagens, desenvolvimento pessoal, conforto, diversão e aprendizados culturais.

Diante desse conceito, estende-se a terminologia "turismo infantil" para além da concepção, tão somente, da idade, suscitando a necessidade de um turismo adequado para atender, efetivamente, às crianças turistas, contribuindo para o bem estar tanto das crianças, quanto de seus responsáveis. Esta concepção propiciará também aos vários setores do turismo, uma oportunidade de diferenciação de seus produtos e serviços, o que gerará qualidade e humanização no turismo.

\section{CONSIDERAÇÕES FINAIS}

Refletir sobre a humanização do turismo, preconizando o chamado "turismo para todos" indica que é essencial os produtos e serviços turísticos estarem adequados a 
todas as pessoas; nesse sentido, atentando para a questão qualitativa do turismo. Por sua vez, crianças, enquanto turistas, requerem uma série de cuidados, posto que possuem necessidades temporárias, tais como o tamanho adequado de mobiliário; a programação de lazer direcionada; a capacitação (e sensibilidade) dos profissionais de turismo para atender tal público e a preservação da integridade física.

No presente trabalho, considera-se que a importância do turismo para as crianças ficou evidenciada, denotando que a viagem ou o passeio turístico pode ser um exercício prático para expandir os olhares das crianças, buscando a compreensão dos lugares que expressem diferentes paisagens e manifestações culturais.

Assim sendo, faz-se mister sugerir atividades práticas que levem as crianças a refletirem e apreenderem o meio ambiente e a cultura, com enfoque na identidade cultural do local e/ou da região, a qual o empreendimento (ou atrativo) turístico está inserido.

A importância das crianças para o turismo tem suporte nas pesquisas sobre tendências do setor, que mencionam o turismo infantil como um dos mercados emergentes. Ademais, há que se aprofundarem os estudos sobre a questão da forte influência dos filhos sobre os pais, especificamente, no consumo do turismo.

Transcendendo o fato que produtos e serviços turísticos sejam práticos e esteticamente adequados às crianças e cômodos para os pais, urge criar condições às crianças para a apropriação e significação do consumo que lhes acrescentem em termos culturais, que as dignifiquem como seres em formação e como "consumidoras-cidadãs".

As constatações demonstram a importância de existirem lugares propícios ao turismo infantil e sinalizam o interesse dos gestores da atividade turística em apurar o olhar, desenvolvendo com critérios, humanização e profissionalismo o turismo adequado e satisfatório para as crianças, para os pais e/ou responsáveis.

A proposta conceitual para "turismo infantil" destaca a necessidade de um turismo adequado para atender às crianças turistas com qualidade e segurança. Nessa proposta, as atividades comumente relacionadas ao turismo infantil foram elencadas, no entanto, há que se notar que tal feito não desapropria as crianças de estarem presentes em outros tipos de turismo, tais como o de aventura e o ecoturismo. 
Por fim, a proposta busca alargar o horizonte para com o turismo infantil, na tentativa de ser uma reflexão tanto no meio acadêmico quanto no mercado turístico; e, principalmente, suscitar um olhar mais atento às crianças turistas.

\section{REFERÊNCIAS}

ALAYA. Disponível em: <http://www.alaya.com.br>. Acesso em: 08/06/2012.

AlCOBIA, R. A. Dimensões da hospitalidade nos parques temáticos. $139 \mathrm{f}$. Dissertação (Mestrado em Hospitalidade), Universidade Anhembi Morumbi, São Paulo, 2004.

AGUIRRE, R. S.; DI SANTO, S.; GRUNEWALD, L.; PANTANO, L.; SIMON, M. F. G. Recreação e turismo para todos. Caxias do Sul: EDUCS, 2003.

ANDRIOLO, A.; FAUSTINO, E. Educação, turismo e cultura: a experiência de estudantes paulistas em Uruçunga. In: RODRIGUES, A. B. (Org.). Turismo: desenvolvimento local. São Paulo: Hucitec, 1999. p. 164-178.

ARIÈS, P. História social da criança e da família. Tradução: Dora Flaksman. 2. ed., Rio de Janeiro: Guanabara, 1981. 279 p.

ÁVILA, M. A. Lazer e recreação. Apostila apresentada ao curso de Animação Turística (mimeo.). Florianópolis, nov. 2006. 94 p.

BAHL, M. Produção Turística e Efeitos Sociais, Econômicos e Culturais no Espaço Urbano e Regional. Aula proferida no Programa de Pós-Graduação em Geografia da Universidade Federal do Paraná. Curitiba: UFPR, 2012. Notas de Aula.

BRASIL. Lei n. 8069, 13 de julho de 1990. Dispõe sobre o Estatuto da Criança e do Adolescente e dá outras providências (ECA). Brasília, DF, 1990. Disponível em <http://www.planalto.gov.br/ccivil 03/leis/18069.htm>. Acesso em: 08/06/2012.

CANCLINI, N. G. Consumidores e cidadãos: conflitos multiculturais da globalização. Tradução: Maurício S. Dias e Javier Rapp. 4. ed. Rio de Janeiro: Ed. UFRJ, 1999. 266 p.

CASTELLI, G. Administração hoteleira. Caxias do Sul: EDUCS, 2000. 
CIVATATE, H. Acampamento: organização e atividades. Rio de Janeiro: Sprint, 2000. $151 \mathrm{p}$.

COBRA, M. Marketing de serviços: turismo, lazer e negócios. São Paulo: Cobra, 2005. $255 \mathrm{p}$.

COOPER, C.; FlETCHER, J.; FYALL, A; GILBERT, D.; WANHILL, S. Turismo: princípios e práticas. 2. ed. Porto Alegre: Bookman, 2001. 784 p.

DEL PRIORE, M. Apresentação. In: DEL PRIORE, M. (Org.) História das crianças no Brasil. São Paulo: Contexto, 2000. p. 8-18.

FÉRIAS VIVAS. In: Pesquisa Férias Vivas - Pais. Disponível em: $<$ http://www.feriasvivas.org.br>. Acesso em: 08/06/2012.

FERREIRA, R. L.; GOMES, F. T. M. C.; SILVA, M. S. Uso da cartilha "Aventura da vida nas cavernas" como ferramenta de educação nas atividades de turismo em paisagens cársticas. Pesquisa em Turismo e Paisagens Cársticas. v. 1, n. 2, p. 145164. 2008. Disponível em:〈http://www.sbe.com.br/turismo.asp〉. Acesso em: $25 / 09 / 2012$

FLORES, P. S. O. Treinamento em qualidade - fator de sucesso para o desenvolvimento de hotelaria e turismo. São Paulo: Roca, 2002. 204 p.

FROMER, B.; VIEIRA, D. D. Turismo e terceira idade. São Paulo: Aleph, 2003. 93 p.

GUIA QUATRO RODAS Brasil 2008. São Paulo: Abril, 2008.

GIDDENS, A. Mundo em descontrole: o que a globalização está fazendo de nós. 3. ed. Rio de Janeiro: Record, 2003. 108 p.

HORTA, M. L. P.; GRUNBERG, E.; MOTEIRO, A. Q. Guia básico de educação patrimonial. Brasília: Instituto do Patrimônio Histórico e Artístico Nacional, Museu Imperial, 1999. $65 \mathrm{p}$.

KRAMER, S. Pesquisando Infância e educação: um encontro com Walter Benjamin. In: KRAMER, S.; LEITE, M. I. (Orgs.) Infância: fios e desafios da pesquisa. Campinas: Papirus, 1996. p. 14 -38.

KUHLMANN JÚNIOR, M.; FERNANDES, R. Sobre a história da infância. In: FARIA FILHO, L. M. (Org.). A infância e sua educação - matérias, práticas e representações (Portugal e Brasil). Belo Horizonte: Autêntica, 2004. p. 15-33. 
KUSHANO, E. S. Adequação de produtos e serviços turísticos para a criança: um olhar para os meios de hospedagem. 141 f. Dissertação (Mestrado em Cultura e Turismo). 141 f. Universidade Estadual de Santa Cruz, Ilhéus, 2008.

Adequação de meios de hospedagem para crianças: um foco no Ecoresort Tororomba, Distrito de Olivença, Ilhéus, Bahia. In: Revista Hospitalidade, ano 4, n. 1. São Paulo: Anhembi Morumbi, 2007. p. 49-62.

LIVROS de Turismo. Disponível em: <http://www.livrosdeturismo.com.br>. Acesso em: $12 / 05 / 2012$.

MARCELLINO, N. C. Estudos do lazer - uma introdução. 4. ed. Campinas: Autores Associados, 2006. 100 p.

NEGRINE, A.; BRADACZ, L.; CARVALHO, P. E. G. Recreação na hotelaria: o pensar e o fazer lúdico. Caxias do Sul: EDUCS, 2001. 128 p.

OMT (Organização Mundial do Turismo). Turismo internacional começa forte em 2012. Tradução: Google. Disponível em: <http://unwto.org/>. Acesso em: 12/05/2012.

Turismo internacional: uma perspectiva global. 2. ed. Tradução: Roberto Cataldo Costa. Porto Alegre: Bookman, 2003. 254 p.

PELIZZER, H. A. Planejamento e gestão da hospitalidade no turismo receptivo. In: DENCKER, A. F. M. (Org.). Planejamento e gestão em turismo e hospitalidade. São Paulo: Pioneira Thomson Learning, 2004. p. 45-73.

PEÑAlBA, J. L. Teoría y práctica de la educación en el tiempo libre. Madri: Editorial CCC, 1999. 428 p.

PEREIRA, R. M. R.; SOUZA, S. J. Infância, conhecimento e contemporaneidade. In: KRAMER, S.; LEITE, M. I. (Orgs.) Infância e produção cultural. São Paulo: Papirus, 2005. p. 25-42.

PIMENTEL, G. G. A. Lazer: fundamentos, estratégias e atuação profissional. Jundiaí: Fontoura, 2003. $112 \mathrm{p}$.

PIRES, M. J. Lazer e turismo cultural. São Paulo: Manole, 2002. 139 p.

POPCORN, F.; HANFT, A. O dicionário do futuro: as tendências e expressões que definirão nosso comportamento. Rio de Janeiro: Campus, 2002. 413 p. 
PROUT, A. The future of childhood: towards the interdisciplianry study of children. New York: Routledge Falmer, 2005. 361 p.

PUBLICAÇÕES DE TURISMO. Disponível em: <http://www.publicacoesdeturismo.com.br>. Acesso em 24/09/2012.

SARMENTO, M. J.; PINTO, M. As crianças e a infância: definindo conceitos, delimitando o campo. In: PINTO, M.; SARMENTO, M. J. (Orgs.) As crianças, contextos e identidades. Braga, Portugal. Universidade do Minho. Centro de Estudos da Criança. Ed. Bezerra, 1997, p. 7-30.

SARMENTO, M. J. As culturas da infância nas encruzilhadas da segunda modernidade. In: SARMENTO, M. J.; CERISARA, A. B. Crianças e miúdos: perspectivas sociopedagógicas da infância e da educação. Porto: Edições Asa, 2004. p. 9-34.

Imaginário e culturas da infância. Cadernos de educação, Pelotas, v. 12, n. 21, p. 51-69, 2003.

SILVA, F. S. S. Turismo e psicologia no envelhecer. São Paulo, Roca: 2002. 82 p.

SILVA, T.; KUSHANO, E. S.; ÁVILA, M. A. Segmentação de mercado: uma abordagem sobre o turismo em diferentes faixas etárias. Caderno Virtual de Turismo. v. 8, n. 2, p. 105-114. 2008. Disponível em:

<http://www.ivt.coppe.ufrj.br/caderno/>Acesso em: 25/09/2012

SÍTIO DO CARROÇÃO. Sítio do Carroção. Disponível em: <http://www.carrocao.com.br>. Acesso em: 08/06/2012.

SPÍNOLA DA HORA, A. S.; CAVALCANTI, K. B. Turismo pedagógico: conversão e reconversão do olhar. In: REJOWSKI, M.; COSTA, B. K. (Orgs.) Turismo contemporâneo: desenvolvimento, estratégia e gestão. São Paulo: Atlas, 2003. p. 207227.

STEINBERG， S. R.; KINCHELOE, J. L. Introdução. In: STEINBERG, S. R.; KINCHELOE, J. L. (Orgs.). Cultura infantil: a construção corporativa da infância. Rio de Janeiro: Civilização Brasileira, 2001. p. 10-49.

STOPPA, E. A. Acampamentos de férias. Campinas: Papirus, 1999. 100 p.

SWARBROOKE, J. O comportamento do consumidor no turismo. Tradução: Saulo Krieger. São Paulo: Aleph, 2002. 408 p. 
TUAN, Y. Topofilia. Um estudo da percepção, atitudes e valores do meio ambiente. Tradução: Lívia de Oliveira. São Paulo: Difel, 1980. p. 52-67.

UNIÃO DOS ESCOTEIROS DO BRASIL. Qual o propósito do movimento escoteiro? Disponível em: < http://www.escoteiros.org.br >. Acesso em: 08/06/2012.

VAZ, G. N. Marketing turístico: receptivo e emissivo: um roteiro estratégico para projetos mercadológicos públicos e privados. São Paulo: Thomson Pioneira, 1999. 296 p.

VYGOTSKY, L. S. A formação social da mente: o desenvolvimento dos processos psicológicos superiores. 4. ed. São Paulo: Martins Fontes, 1991.

WELLS, N.; KRISTIS, L. Nature and the life course: pathways from childhood nature experiences to adult environmentalism. Journal Children, Youth and Environments (CYE). n. 16. p. 1-14. 2006. Disponível em: 〈http://www.colorado.edu/journals/cye/>. Acesso em: 12/03/2012.

WAINBERG, J. Turismo, comunicação e informação. Apostila apresentada ao curso de pós-graduação Comunicação e Turismo, em nível de extensão, da Universidade Metodista de São Paulo - UMESP. Maringá, 2002.

Recebido em: 28-06-2012.

Aprovado em: 28-07-2012. 